\title{
Penile Cancer cM0 TNM Finding v7
}

National Cancer Institute

\section{Source}

National Cancer Institute. Penile Cancer CMO TNM Finding v7. NCI Thesaurus. Code C89192.

Penile cancer without evidence of distant metastasis. (from AJCC 7th Ed.) 